\title{
Article \\ Assessment of the Impact of Material Selection on Aviation Sustainability, from a Circular Economy Perspective
}

\author{
Dionysios N. Markatos * and Spiros G. Pantelakis
}

Citation: Markatos, D.N.; Pantelakis, S.G. Assessment of the Impact of Material Selection on Aviation Sustainability, from a Circular Economy Perspective. Aerospace 2022, 9, 52. https://doi.org/10.3390/ aerospace 9020052

Academic Editor: Konstantinos Kontis

Received: 2 December 2021

Accepted: 10 January 2022

Published: 20 January 2022

Publisher's Note: MDPI stays neutral with regard to jurisdictional claims in published maps and institutional affiliations.

Copyright: (C) 2022 by the authors. Licensee MDPI, Basel, Switzerland. This article is an open access article distributed under the terms and conditions of the Creative Commons Attribution (CC BY) license (https:// creativecommons.org/licenses/by/ $4.0 /)$.
Laboratory of Technology \& Strength of Materials, Department of Mechanical Engineering \& Aeronautics, University of Patras, 26500 Patras, Greece; pantelak@mech.upatras.gr

* Correspondence: dmark@upatras.gr
Abstract: Climate change and global warming pose great sustainability challenges to the aviation industry. Alternatives to petroleum-based fuels (hydrogen, natural gas, etc.) have emerged as promising aviation fuels for future aircraft. The present study aimed to contribute to the understanding of the impact of material selection on aviation sustainability, accounting for the type of fuel implemented and circular economy aspects. In this context, a decision support tool was introduced to aid decisionmakers and relevant stakeholders to identify and select the best-performing materials that meet their defined needs and preferences, expressed through a finite set of conflicting criteria associated with ecological, economic, and circularity aspects. The proposed tool integrates life-cycle-based metrics extending to both ecological and economical dimensions and a proposed circular economy indicator (CEI) focused on the material/component level and linked to its quality characteristics, which also accounts for the quality degradation of materials which have undergone one or more recycling loops. The tool is coupled with a multi-criteria decision analysis (MCDA) methodology in order to reduce subjectivity when determining the importance of each of the considered criteria.

Keywords: circular economy; CEI; holistic tool; decision-making tool; aviation sustainability; material selection

\section{Introduction}

Emissions from the aviation industry are of increasing concern to governments, policymakers, and the flying public as environmental issues such as climate change and global warming pose great sustainability challenges to the aviation industry [1,2]. It is estimated that 920 million tons of $\mathrm{CO}_{2}$ were emitted due to global aviation operations for both passenger and cargo carriage in 2019 alone [3]. In contrast to road transportation, the long lifetime of aircraft (20-30 years) implies a doubling or tripling of aviation-induced $\mathrm{CO}_{2}$ emissions until 2050 unless radical changes are made [4]. Therefore, it is crucial to consider sustainable approaches and solutions when it comes to future aircraft.

To this end, weight reduction through the implementation of low-density polymer composites to replace heavier materials is a major aim of the aviation sector [5]. Carbonfiber-reinforced polymers (CFRP) are widely utilized in aviation applications for weight reduction to meet fuel efficiency objectives and, consequently, to decrease the environmental burden of the aviation industry. However, issues such as the great environmental and financial burden associated with the production of virgin carbon fibers, as well as difficulties associated with their recycling, continue to pose great challenges [5,6]. It is worth noting that nearly $98 \%$ of end-of-life CFRP components/parts and manufacturing composite CFRP waste end up in landfills [7].

The principal approach to mitigate the consequences of aviation on climate change focuses on the use of alternative aircraft fuels. Currently, the aviation industry uses fuels derived from fossil-based carbon sources which are mostly specialized forms of petroleum-based fuels and are primarily kerosene-based [8]. Of the alternative fuels under investigation, hydrogen appears to be a very promising fuel for sustainable transportation 
due to its ability to provide clean, reliable, safe, and affordable energy $[9,10]$. Nevertheless, despite the promise of hydrogen-fueled aircraft, further research is needed to realize their commercial potential in the aviation sector [8].

To meet the goals of sustainable development, the implementation of circular economy (CE) principles is increasingly in demand, while new tools are required in order to assist decision-makers, practitioners, and policymakers in achieving CE objectives [11]. As was highlighted in [12], the current LCA approaches cannot adequately assess the circularity of a system as they consider the linear economy a point of reference. On the other hand, the circularity indicators and metrics which have been developed over recent years in order to measure the circularity of a product or system present inconsistencies regarding their scope, aims, and applications, rendering their implementation and interpretation a complex task; moreover, they can only provide a partial view of a system's performance. Several examples at the material/component level have shown that the most circular option is not necessarily the environmentally preferable one, which can lead to contradicting results and conclusions when applying either LCA or CE principles [12,13]. To address this, attempts have been made to integrate LCA and circularity indicators; however, such undertakings are currently in the early conceptualization stage and are not yet related to the aviation sector [12,14]. Moreover, they do not extend the life cycle perspective into other dimensions, such as the economic one [15]. To the best of the authors' knowledge, there exists a lack of tools in the aviation industry capable of assessing the performance of a new material by considering both sustainability and circularity metrics and aspects.

In the above context, when considering material selection from a wide range of potential options - especially in aviation - it is important to include a technical or quality feature in the evaluation phase, as the considered components present a design envelope with mechanical performance limits and specific manufacturing requirements [16]. The aim of the present study was to provide a decision support tool that can eventually assist decision-makers and relevant stakeholders to identify and select the best-performing materials that meet their defined needs and preferences, expressed through a finite set of conflicting criteria associated with technical, ecological, economic, and circularity aspects. The proposed tool accounts for the dependency of the impact of the material selection on the sustainability and circularity of an aircraft component or subsystem due to the type of fuel required. This is achieved through the integration of life-cycle-based metrics extending to both ecological and economical dimensions associated with the material and type of fuel used, as well as a suitable circular economy indicator (CEI) related to quality and focused on the material/component level. The aforementioned CEI has the advantage of considering the quality degradation of the materials after one or multiple recycling loops, addressing the notion that circularity cannot be adequately defined and assessed if it does not consider the degradation of materials over repeated recycling loops. Furthermore, the indicator is coupled with a multi-criteria decision analysis (MCDA) methodology in order to reduce subjectivity when determining the significance (i.e., weight) of the considered criteria in order to reach a decision. The novelty of the current tool lies in its ability to aggregate several metrics associated with sustainability and circularity aspects into a single index, and consequently simplify and rationalize the material selection process.

The present paper is structured as follows: initially, the basic considerations of the study are defined. Next, the studied system and the methodology followed are described and the developed decision-making tool is presented in detail. Subsequently, the different materials considered are assessed in terms of their environmental and economic impact over their total life cycle by exploiting LCA and LCC data from the literature. Finally, a holistic assessment of the investigated materials is carried out through implementation of the tool, incorporating environmental, economic, and circularity considerations. 


\section{Materials and Methods}

\subsection{Basic Considerations}

The proposed methodology is applicable to any component of an aircraft. In the present study, the decisive parameters considered were the material type, the manufacturing process involved in producing the component, the recycling process, and the weight of the component. Furthermore, it was assumed that the geometrical features of the component, except for thickness, do not depend on the choice of the material. To carry out the study, a hypothetical panel component of $1000 \mathrm{~kg}$ was assumed as the reference unit to which all comparisons were made. The candidate materials selected for the considered component were a high-performance woven CFRP with $50 \mathrm{wt} \%$ fiber content, whose properties were taken from [17], and an advanced aircraft Al-Li alloy, i.e., aluminum 2198 [18]. In addition, recycled components from CFRP and aluminum were considered and are described in a subsequent section of this manuscript. To comply with design requirements, the mechanical performance of the components in terms of strength and stiffness needed to be identical. To compensate for material property variations between components made of different materials, thickness was treated as a variable which must be adjusted in order to achieve the same mechanical properties for all components, i.e., equal stiffness. Equal stiffness was considered to be a suitable criterion for the comparison of different materials [19], and an approximate formula [20-23] for the calculation of the expected mass ratio $(\mathrm{Rm})$, based on the relative thickness $(\mathrm{Rt})$ and density of the alternative materials, was implemented:

$$
\begin{gathered}
\mathrm{R}_{\mathrm{t}}=\frac{\mathrm{t}_{\mathrm{CFRP}}}{\mathrm{t}_{\mathrm{Al}}}=\left(\frac{\mathrm{E}_{\mathrm{Al}}}{\mathrm{E}_{\mathrm{CFRP}}}\right)^{\frac{1}{\lambda}} \\
\mathrm{R}_{\mathrm{m}}=\frac{\mathrm{m}_{\mathrm{CFRP}}}{\mathrm{m}_{\mathrm{Al}}}=\frac{\mathrm{P}_{\mathrm{CFRP}}}{\mathrm{P}_{\mathrm{Al}}}\left(\frac{\mathrm{E}_{\mathrm{Al}}}{\mathrm{E}_{\mathrm{CFRP}}}\right)^{\frac{1}{\lambda}}
\end{gathered}
$$

where $\mathrm{t}$ is the material thickness, $\mathrm{m}$ is the material mass, $\mathrm{p}$ is the material density, $\mathrm{E}$ is the material modulus, and $\lambda$ is a parameter that depends on the design purpose and may vary between 1 and 3: $\lambda=1$ is appropriate for components under tension loading and is selected as the relevant case here, $\lambda=2$ is for columns and beams under bending and compression conditions in one plane, and $\lambda=3$ is suitable for plates and flat panels when loaded under bending and buckling conditions in two planes. However, it should be noted that actual component designs require a finite element analysis to identify the material design index that would ensure design constraints are met.

\subsection{Studied System and Methodological Framework}

To comply with the goals and objectives of a circular economy, the ecological and economic impact of the investigated materials were assessed by extending the study scope from cradle to cradle; i.e., the end-of-life of the product involves a recycling process for material recovery and further remanufacturing of high-quality recycled materials. To evaluate the environmental and economic impact associated with the materials used in order to produce aircraft components, an LCA and LCC data-driven analysis was conducted. Data were collected from the best and most recent scientific literature as well as from relevant technical datasheets, and the present analysis was developed as a spreadsheet model. In this context, environmental impact was assessed through the calculation of GHG emissions associated with the production, manufacturing, and recycling phases of the considered components (expressed as $\mathrm{kgCO}_{2}$ eq per component mass) or the component weight-dependent GHG emissions associated with the type of fuel used (expressed as $\mathrm{kgCO}_{2} \mathrm{eq}$ per component mass-km). The associated GHG emissions were considered in the present study as they are the most widely reported environmental impact metric across industry and academia [16]. The economic impact of the investigated components was also assessed, where costs refer to either the process-related energy costs associated with the production, manufacturing, and recycling phases (expressed per component mass) or the cost of fuel (based on fuel consumption and expressed per component mass- $\mathrm{km}$ ) when assessing the impact of the 
use phase for the considered components. The non-household price of kWh in Germany was considered [24] for calculation of the process-related energy costs.

The life cycle assessment starts with the primary material production, i.e., aluminum ingot [18], carbon fibers (PAN-based), and epoxy resin [16,25-27]. For the manufacturing process of aluminum components, roll forming was considered to be a material-efficient and, therefore, a leaner process for aluminum parts and assemblies [18,28]. For the CFRP component, resin transfer molding (RTM) was chosen as one of the main composite manufacturing processes used in aeronautics $[29,30]$. A buy-to-fly ratio (weight of the raw material purchased compared with the weight of the final part) of 1:1 was assumed in assessment of the impact of the manufacturing processes due to a lack of relevant data. Regarding the manufacturing of recycled components, the environmental and economic impact of the upgrade technologies for fibers (e.g., alignment, sizing) was similarly not taken into consideration due to a lack of relevant data in the literature.

For any given aircraft component, the use phase dominates its overall environmental impact [16]. In this phase, said impact is directly linked to the weight of the component [16]. To assess the impact of mass reduction on the emissions and costs associated with the use phase, a quantitative description of the mass-induced fuel consumption during vehicle use is required [31]. In the present study, fuel consumption was assumed to be proportional to the component mass $[19,32]$. Hence, both CFRP and aluminum components were considered as loads that must be carried by the aircraft during each flight. In this context, the results presented here are given in a service function unit, i.e., per component mass-km, which represents a wider approach for all aircraft classes and types regardless of the split between passengers and cargo payloads onboard [10]. To assess the impact of material selection on the use phase of the considered components and accounting for the type of fuel used, GHG emissions and costs associated with the type of fuel implemented were adapted from [10], where a complete life cycle analysis of an aircraft running on different fuels was conducted including the production phase of the required aviation fuel. To assess the use phase impact of the components, the average lifetime distance of an Airbus A320 was calculated based on the number of flying hours for which it was designed, i.e., 60,000 flying hours over a 25 -year lifespan, and its average economical cruising speed, i.e., $840 \mathrm{~km} / \mathrm{h}[33,34]$. The environmental and financial impact of two different fuels were investigated in the present study; namely, kerosene and liquid hydrogen.

Recycling of aluminum alloys involves remelting and subsequently, casting into ingots [18]. Although the properties of the recycled and remelted alloys usually resemble those of the initial materials, they are specifically exploited for manufacturing non-critical components as the performance requirements and composition of alloys are different nowadays compared with those of older planes $[35,36]$. Regarding the recycling of CFRPs, the fluidized bed process (FBP) was considered in this study as being a promising recycling technique for CFRPs that can recover carbon fibers with mechanical properties comparable to those of virgin ones [23]. FBP is currently in the pilot phase and at technological readiness level 6; in contrast, other recycling methods which seem quite promising, such as solvolysis, are still in the laboratory stage [37].

It is evident that future research efforts should concentrate on recycling technologies that can reclaim high-quality constituents and remanufacture them into materials with high performance, ideally with the goal of achieving performance equivalent to virgin CF [38]. To assess and compare the environmental and financial impact of the end-of-life process under the prism of closed-loop (or to be more accurate, semi-closed-loop) recycling of the materials investigated, realistic recycling pathways must be considered. Semi-closedloop refers to cases where the recycled material is used in aviation applications, although with a different material quality when compared with the initial material. In the present study, potential recycling pathways were identified and life cycle emissions and costs were calculated and compared for the investigated CFRP and aluminum components against the background of the above approach; i.e., the recycled materials are intended for use in secondary aviation applications. Degradation of the fibers after a second recycling 
loop was also accounted for when assessing the impact of recycled CFRP components. The properties of the components containing recycled carbon fibers after the first recycling loop were taken from [17], while the data associated with mechanical property degradation of recycled CF parts after a second recycling loop were taken from [39]. Equation (2) was implemented for the calculation of the mass of the recycled components and compensates for variations in material properties due to degradation of the recyclates.

\subsection{Definition of the Decision-Making Holistic Tool}

The tool implemented in the current study to assess the performance of the investigated components is an adaptation of a holistic approach initially introduced in [40]. The proposed model has been successfully implemented as a decision-making tool to aid stakeholders in selecting appropriate manufacturing methods [40] and recycling processes [6] while accounting for the technical, ecological, and economic features of the materials and/or processes applied. A quantitative index was derived as an output of the approach introduced in [40]:

$$
\mathrm{P}=\mathrm{K}_{\mathrm{Q}} \cdot \mathrm{Q}-\mathrm{K}_{\mathrm{C}} \cdot \mathrm{C}-\mathrm{K}_{\mathrm{E}} \cdot \mathrm{E}
$$

where $\mathrm{P}$ is the holistic index, $\mathrm{Q}$ is the selected technical/quality feature of the investigated material, $\mathrm{C}$ refers to the cost of the material/process, and $\mathrm{E}$ is the environmental footprint of each material/process. $\mathrm{K}_{\mathrm{Q}}, \mathrm{K}_{\mathrm{C}}$, and $\mathrm{K}_{\mathrm{E}}$ are dimensionless weight factors which reflect the importance of each term to the overall value of the index.

To aid in material selection for aviation applications toward the goal of sustainability and compliance with the principles and objectives of $\mathrm{CE}$, the modified formula presented herein integrates the ecological and economic metrics associated with the investigated material and a CEI which can be evaluated at the material/component/subsystem level. However, appropriate metrics need to be defined for each level as the specific stiffness considered in the present study represents an example of oversimplification. Terms $\mathrm{E}$ and $\mathrm{C}$ of the adapted index refer to the environmental and economic impact of the component/material, respectively, accounting for the life cycle phases as described in Section 2.2. The corresponding life cycle metrics for $\mathrm{E}$ and $\mathrm{C}$ are calculated on a normalized basis (relative to the material demonstrating the larger ecological or economic impact):

$$
\begin{aligned}
& E=\frac{E_{m}}{E_{\text {ref }}} \\
& C=\frac{C_{m}}{C_{\text {ref }}}
\end{aligned}
$$

where $\mathrm{E}_{\mathrm{m}}$ is the environmental impact of the investigated material/component, $\mathrm{E}_{\mathrm{ref}}$ is the environmental impact of the reference material/component (the one with highest environmental emissions among the candidate materials/components considered), $C_{m}$ is the economic impact of the investigated material/component, and $\mathrm{C}_{\text {ref }}$ is the economic impact of the reference material/component (the one with greatest cost among the candidate materials/components considered). The normalized term values range between 0 and 1 , with 0 indicating a fictitious component with zero environmental impact and cost, while 1 corresponds to a component with the same environmental impact and cost as the reference component.

To define a suitable circular economy indicator, the principal postulate made states that the most circular solution is the one demonstrating the highest quality, considering that low-quality recyclates have a direct and significant negative impact on the environment and costs $[6,16]$. Thus, the quality term $Q$ from Equation (2) must be expressed through a circular economy technical/quality aspect. In this frame, $Q$ is expressed through a material's specific properties. More specifically, it is expressed as the ratio of the specific 
stiffness of the reference material to the corresponding specific stiffness of the recycled one, either after the first or a subsequent recycling loop:

$$
\mathrm{Q}=\mathrm{CEI}_{\mathrm{Q}}=\frac{\mathrm{SP}_{\text {rec }}}{\mathrm{SP}_{\text {ref }}}
$$

where $\mathrm{CEI}_{\mathrm{Q}}$ is the quality-based $\mathrm{CEI}, \mathrm{SP}_{\text {rec }}$ is the specific stiffness (tensile modulus divided by density) of the recycled material, and $\mathrm{SP}_{\text {ref }}$ is the specific stiffness of the reference material. $\mathrm{CEI}_{\mathrm{Q}}$ values range between 0 and 1 , where 1 corresponds to a component made of virgin material or to a recycled component which presents the same mechanical properties as the virgin one for the same weight (i.e., no degradation occurs after recycling). A value of 0 corresponds to a fictitious material with zero stiffness; in the case of CFRP, this could be associated with a recycled material that occurs after a grinding procedure.

To aid stakeholders in identifying the best-performing materials, the proposed model is coupled with a multi-criteria decision analysis (MCDA) tool. Based on the above definitions, the modified formula takes the form:

$$
\mathrm{P}=\mathrm{K}_{\mathrm{CEI}} \cdot \mathrm{CEI}_{\mathrm{Q}}-\mathrm{K}_{\mathrm{C}} \cdot \mathrm{C}-\mathrm{K}_{\mathrm{E}} \cdot \mathrm{E}
$$

Definition of the weight factors $\left(\mathrm{K}_{\mathrm{CEI}}, \mathrm{K}_{\mathrm{C}}\right.$, and $\left.\mathrm{K}_{\mathrm{E}}\right)$ is subjective and reflects the priority criteria of the stakeholders and the specific application. To reduce subjectivity in the definition of weight factors, the analytic hierarchy process (AHP), a widely used and well-established MCDA methodology, was implemented [41-43]. Briefly, AHP is based on the principle of paired comparisons. Paired comparisons are used to compare alternatives with respect to the defined criteria and estimate the weights of the criteria on a scale of 1 to 9 . One (1) means that the considered criteria are equally important, i.e., they contribute equally to the objective. Nine (9) indicates that the selected criterion is extremely more important compared with another criterion. The weight factors were determined using the 'SuperDecisions' software [44]. For a detailed description of the MCDA methodology, the reader may refer to [40]. The output of the proposed tool, i.e., the P index, represents a tradeoff between possible contradicting aspects associated with circularity, the environment, and costs, while also accounting for the type of fuel implemented. This trade-off is visualized through the obtained rankings of the investigated materials/components (both virgin and recycled).

\section{Results and Discussion}

\subsection{Environmental and Economic Impact Comparison}

The environmental and economic impact of the investigated components were calculated while accounting for two different types of fuel, i.e., kerosene and liquid hydrogen. Both virgin and recycled components were considered (Table 1). For the component made of recycled aluminum, stiffness was assumed to be the same as the virgin aluminum alloy $[36,45]$. Regarding the CFRP components, different recycling routes were taken into account, i.e., CFRP with randomly oriented recycled fibers, CFRP with aligned recycled fibers, and CFRP with aligned recycled fibers which have undergone a second recycling loop. As was mentioned in Section 2.1, to compensate for variations in material properties due to the different recycling routes of CFRP, thickness (and by extension mass) was adjusted and calculated from Equation (2) in order for the components to present equal stiffness. Hence, the results (Figures 1-3) are presented per specific component mass.

Figure 1 compares the GHG emissions and costs for virgin and recycled CFRP and aluminum components associated with the raw material production, manufacturing of the component, and reclamation (recovery) of the material through the selected recycling process. The component made of virgin CFRP demonstrated the greatest GHG emissions and the highest costs. That is mainly due to the environmental and economic impact of the production of the raw materials, especially the PAN fibers. The component made of virgin aluminum also demonstrated considerable environmental and economic impact, although 
reduced by approximately $20 \%$ compared with the virgin CFRP component. Recycled components demonstrated a considerable decrease in these values due to the fact that they do not require new raw materials, whose production is very intensive in terms of GHG emissions, energy, and associated costs. The most beneficial scenario concerns the CFRP component made of recycled aligned fibers, followed by the component made of aligned fibers which have undergone a second recycling loop.

Table 1. Investigated components for comparison.

\begin{tabular}{lcccccc}
\hline & & Investigated Components & & Recycled Components \\
\hline & Virgin Components & & & CFRP & CFRP \\
Component weight $(\mathrm{kg})$ & 1000 & CFRP & Aluminum & (random fibers) & (aligned fibers) & (aligned fibers, 2nd loop) \\
\hline
\end{tabular}

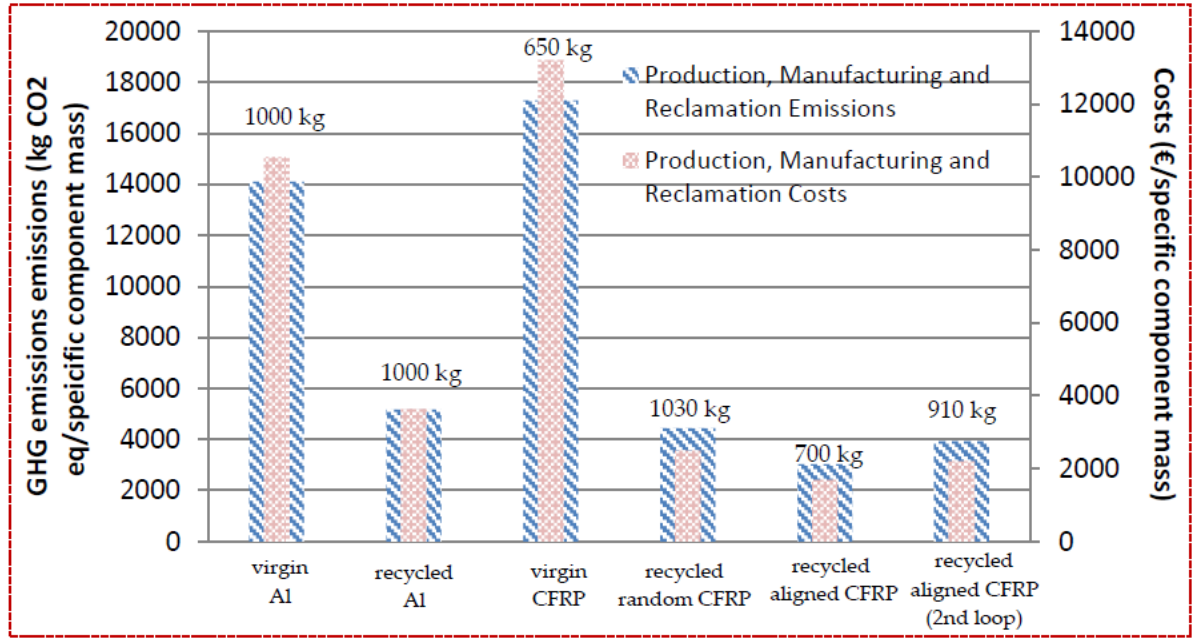

Figure 1. GHG emissions and costs of the investigated components associated with production, manufacturing, and reclamation of the initial materials.

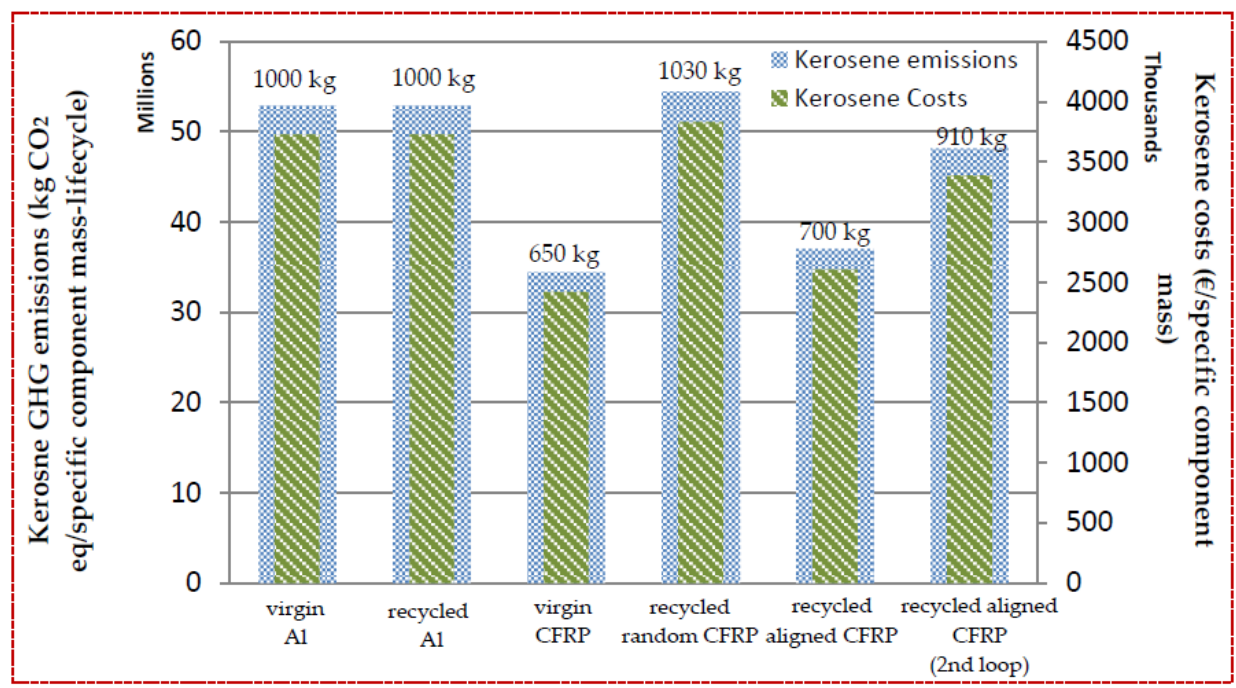

Figure 2. GHG emissions and costs of the investigated components associated with their use phase; kerosene fuel utilized. 


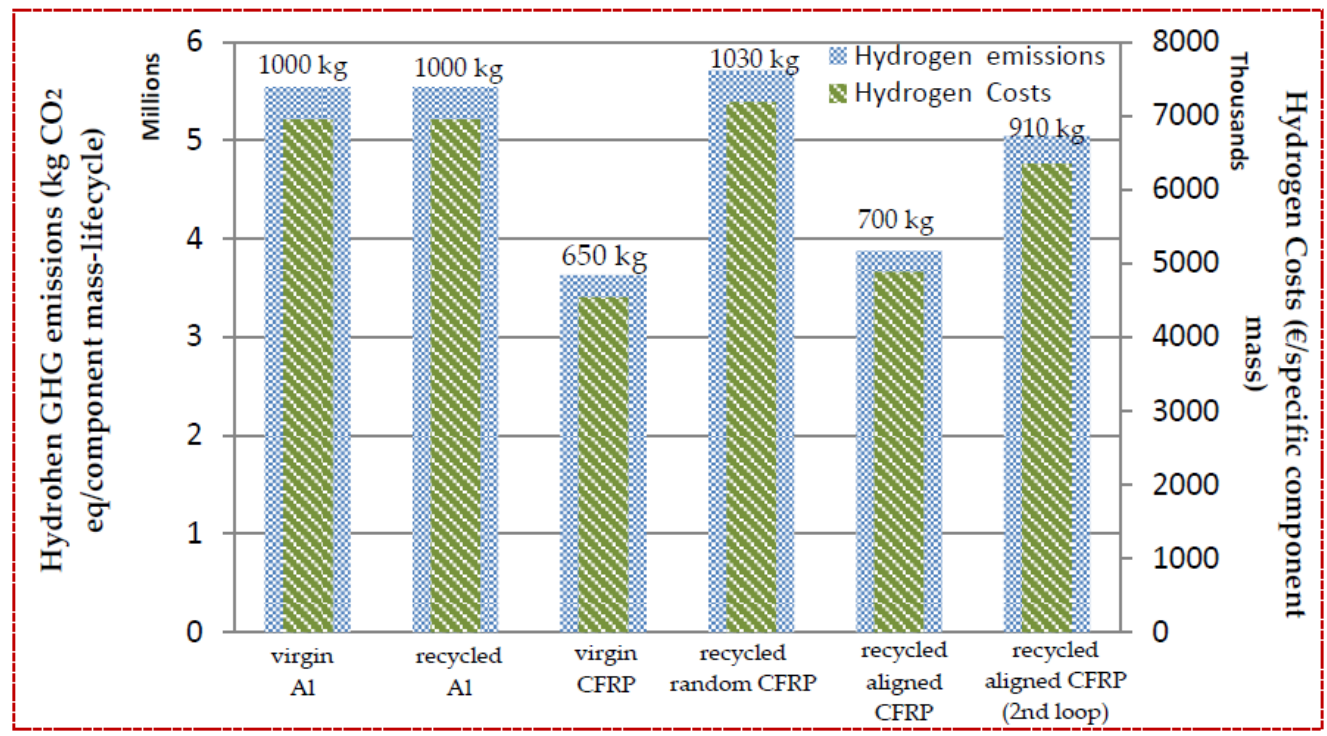

Figure 3. GHG emissions and costs of the investigated components associated with their use phase; liquid hydrogen fuel utilized.

In Figures 2 and 3, the use phases of CFRP and aluminum components (both virgin and recycled) are compared in terms of GHG emissions and costs, accounting for the two different fuels considered, i.e., kerosene and liquid hydrogen. To calculate the demonstrated values, a lifetime average distance of 50.4 million $\mathrm{km}$ was considered based on the Airbus A320 aircraft. The results are directly related to the weight of the considered components. As expected, in aircraft applications, the use phase dominates the life cycle impact of components in terms of their environmental emissions and costs (representing approximately $99 \%$ of the total emissions and costs of the life cycle). The use phase also remains dominant when using liquid hydrogen as a fuel, despite the fact that GHG emissions when using liquid hydrogen are almost $90 \%$ lower than when using kerosene. It should be noted that the above does not apply to less energy intensive transport sectors. For example, in the automotive sector, where a vehicle lifetime distance of approximately $200,000 \mathrm{~km}$ would be considered realistic, the environmental impact associated with virgin CFRP production nearly offsets the corresponding impact associated with the use phase. Therefore, utilization of a recycled CFRP component would clearly demonstrate benefit in this sector.

On the other hand, the use phase costs associated with the utilization of hydrogen are almost double compared with those associated with kerosene due to the currently significant cost of hydrogen fuel. Comparison between the different components considered here indicates that the virgin CFRP component presents the lower GHG emissions and cost by far, owing to its lower weight compared with the alternative components. The CFRP components composed of recycled aligned fibers (after both the first and second recycling loop) seem superior to the aluminum components. Moreover, the recycled CFRP component composed of aligned fibers seemed to compete well with the virgin CFRP component in terms of emissions and costs. Finally, it is noteworthy that even the recycled CFRP component composed of randomly aligned fibers demonstrated GHG emissions and costs comparable to the aluminum components, highlighting the benefits of using lightweight materials such as CFRPs.

It is worth noting that other environmental impacts—such as non-GHG pollutants and resource depletion derived from either the production of CFRP or aluminum alloys or from the use of kerosene or hydrogen fuels-are appreciable and cannot be neglected [10,40]. For instance, bauxite was very recently included in the European Commission's critical raw materials list [46]. Furthermore, environmental emissions were found to be affected by the flight altitude; e.g., in [47]. In this direction, reliable models to assess the overall 
impact on the climate, under a comprehensive life cycle study, are required; however, such investigations lie outside the scope of the present work.

\subsection{Implementation of the Holistic Tool}

To identify the best-performing materials while accounting for the type of fuel used, the holistic tool/index introduced in Section 2.3 was implemented for the assessment and ranking of the different components considered. To demonstrate the feasibility of the tool, eight different combinations of components and fuel types were selected, as shown in Figure 4. To calculate the P index of Equation (7), the quality-based CEI term of Equation (6) was derived using mechanical properties taken from the literature, as described in Section 2.2. Moreover, data associated with the environmental impact and cost were used as inputs for calculation of the Environmental and Cost Terms (Equations (4) and (5)).

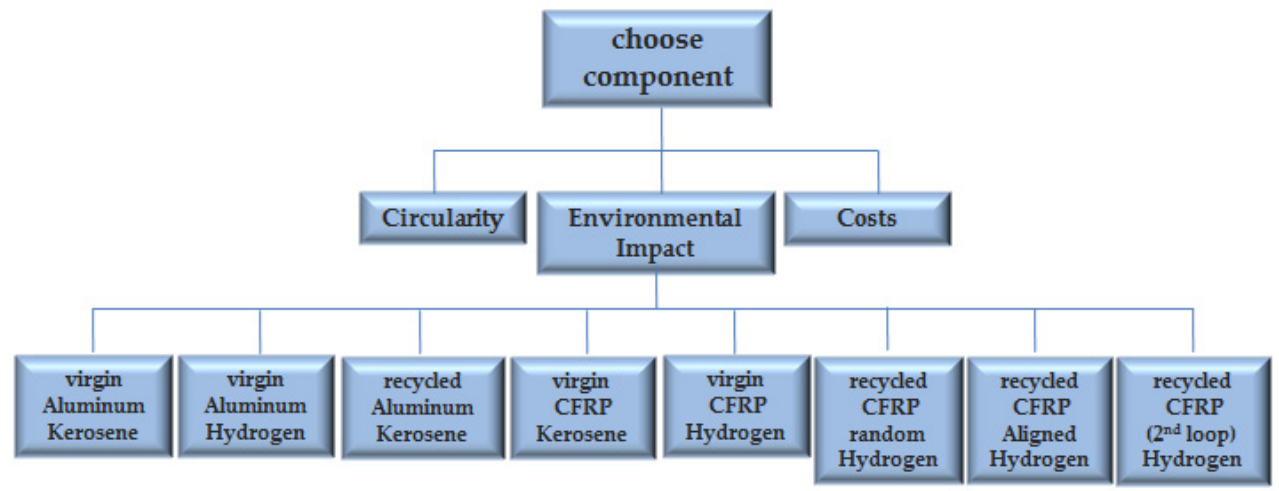

Figure 4. Structure of the AHP model.

\subsubsection{Weight Factors Definition}

To calculate the $\mathrm{P}$ index and compare the different components, dimensionless weight factors were calculated using the AHP method. The AHP matrix is shown in Figure 4. To derive the weight factors of Equation (7) through the AHP process described in Section 2.3, the importance intensities for the paired criteria comparisons were defined and the resulting weight factors were calculated. The results are sensitive to the importance definition in deriving the weigh factors; therefore, three different analyses were conducted by varying the criteria weights of Circularity, Environmental Impact, and Costs (Tables 2-4). In the first comparison analysis (Table 2), Circularity, Environmental Impact, and Costs were assumed to be of equal importance. The second comparison analysis (Table 3) assumed that Circularity is of equal importance to Environmental Impact, while both are 'equally to moderately' more important than Costs. Finally, the third comparison analysis (Table 4) assumed that Environmental Impact is of equal importance to Costs while Circularity is 'equally to moderately' more important than Environmental Impact and Costs.

Table 2. Pairwise comparison matrix: comparison analysis number 1.

\begin{tabular}{ccccc}
\hline & Circularity & Environmental Impact & Costs & Weight Factor/Priority \\
\hline Circularity & 1 & 1 & 1 & $\approx 33 \%$ \\
Environmental Impact & 1 & 1 & 1 & $\approx 33 \%$ \\
Costs & 1 & 1 & 1 & $\approx 33 \%$ \\
\hline
\end{tabular}

Table 3. Pairwise comparison matrix: comparison analysis number 2.

\begin{tabular}{ccccc}
\hline & Circularity & Environmental Impact & Costs & Weight Factor/Priority \\
\hline Circularity & 1 & 1 & 2 & $\approx 40 \%$ \\
Environmental Impact & 1 & 1 & 2 & $\approx 40 \%$ \\
Costs & 0.5 & 0.5 & 1 & $\approx 20 \%$ \\
\hline
\end{tabular}


Table 4. Pairwise comparison matrix: comparison analysis number 3.

\begin{tabular}{ccccc}
\hline & Circularity & Environmental Impact & Costs & Weight Factor/Priority \\
\hline Circularity & 1 & 2 & 2 & $\approx 50 \%$ \\
Environmental Impact & 0.5 & 1 & 1 & $\approx 25 \%$ \\
Costs & 0.5 & 1 & 1 & $\approx 25 \%$ \\
\hline
\end{tabular}

\subsubsection{Index Calculation}

The calculated index values for the three different comparison analyses described above and the ranking among the considered components are shown in Figures 5-7, representing the trade-off between circularity, environmental impact, and costs. The contribution of each of the three terms to the final $\mathrm{P}$ index value is also shown in each figure. Based on Equation (7), the CEI term was considered as a 'bonus', while the Environmental and Cost Terms were considered to be 'penalties' and therefore were subtracted from the Circularity Term. Hence, the higher the final value of the $\mathrm{P}$ index, the higher the overall performance of the component considered. In Figure 5, where the three criteria (circularity, environmental performance, and costs) were considered to be of equal importance, the best overall score belongs to the virgin CFRP component when hydrogen fuel was implemented. This is owing to its high quality, as well as to its low environmental impact during the flight phase due to its low weight compared with the alternative components. The recycled component composed of recycled CFRP aligned fibers follows in short distance, owing to its close-to-virgin quality allowing for potential reuse in high-performance applications. The virgin aluminum component, when kerosene fuel was considered, demonstrated the worst score by far-as was expected-due to its lower mechanical properties compared with composites, as well as the high environmental and economic impact associated with its use. Finally, the recycled aluminum components (for both kerosene and hydrogen fuel) presented similar index values to the CFRP component composed of randomly oriented fibers when hydrogen fuel was used.

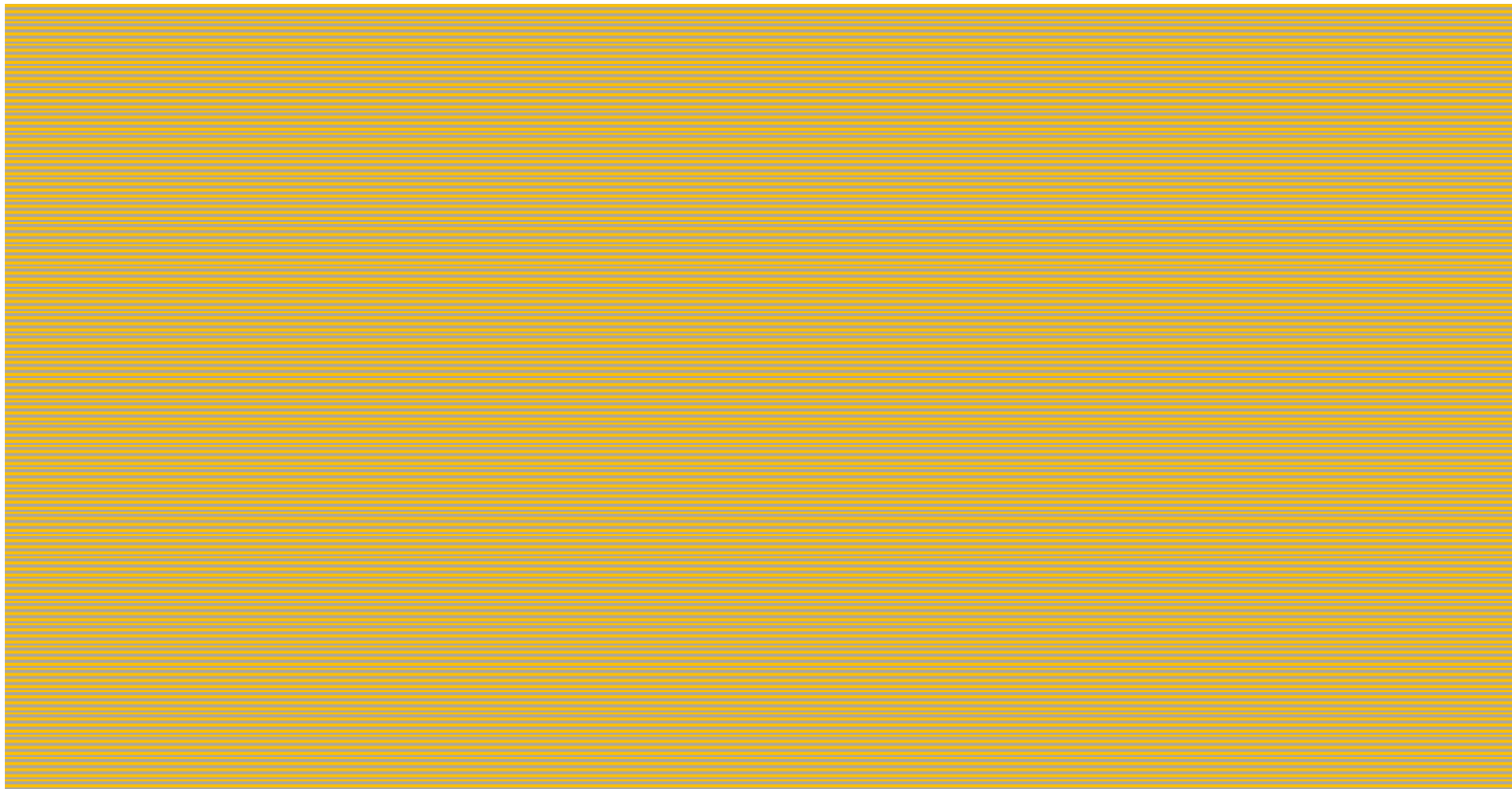

Figure 5. Index term values and final output: comparison analysis number 1. 


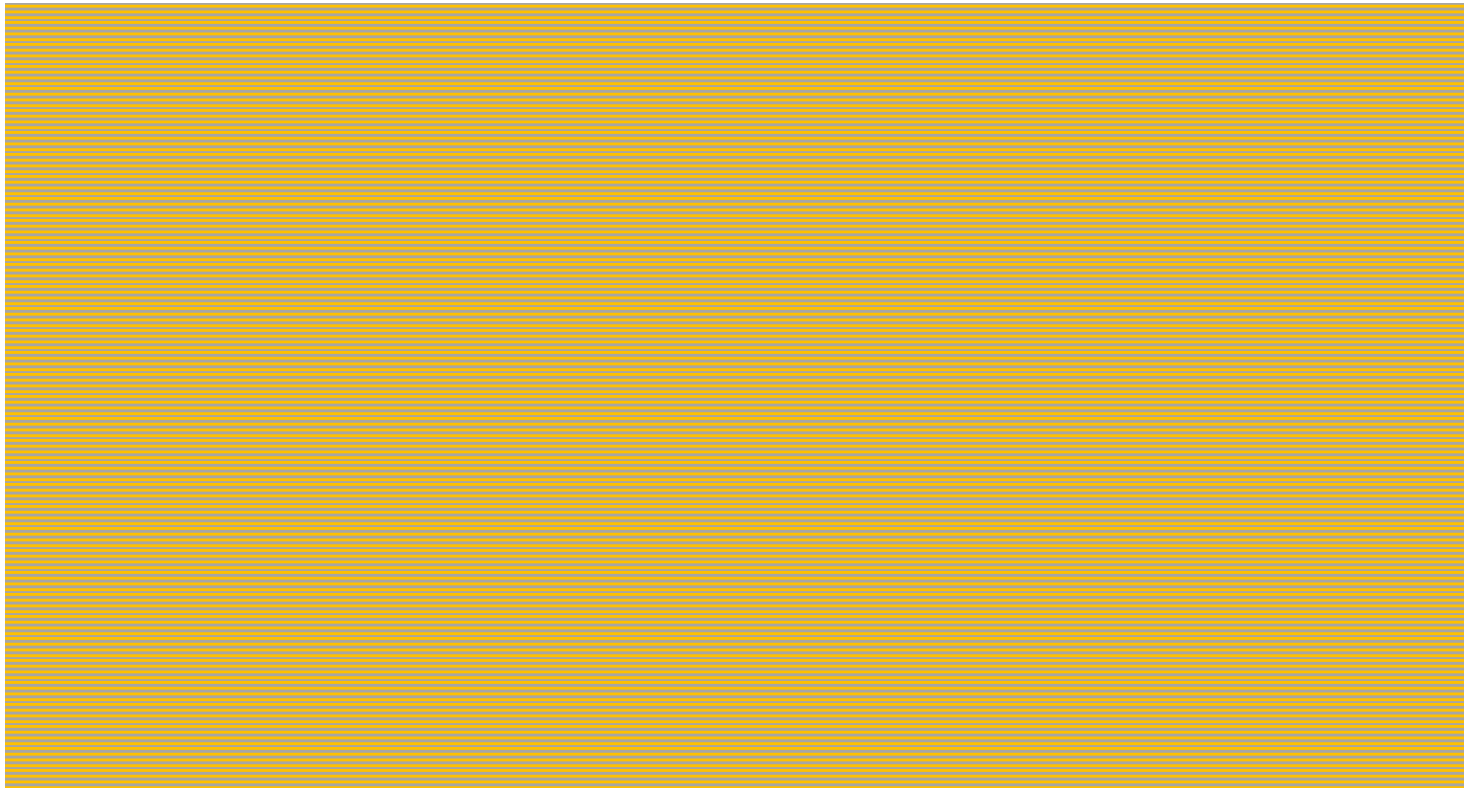

Figure 6. Index term values and final output: comparison analysis number 2.

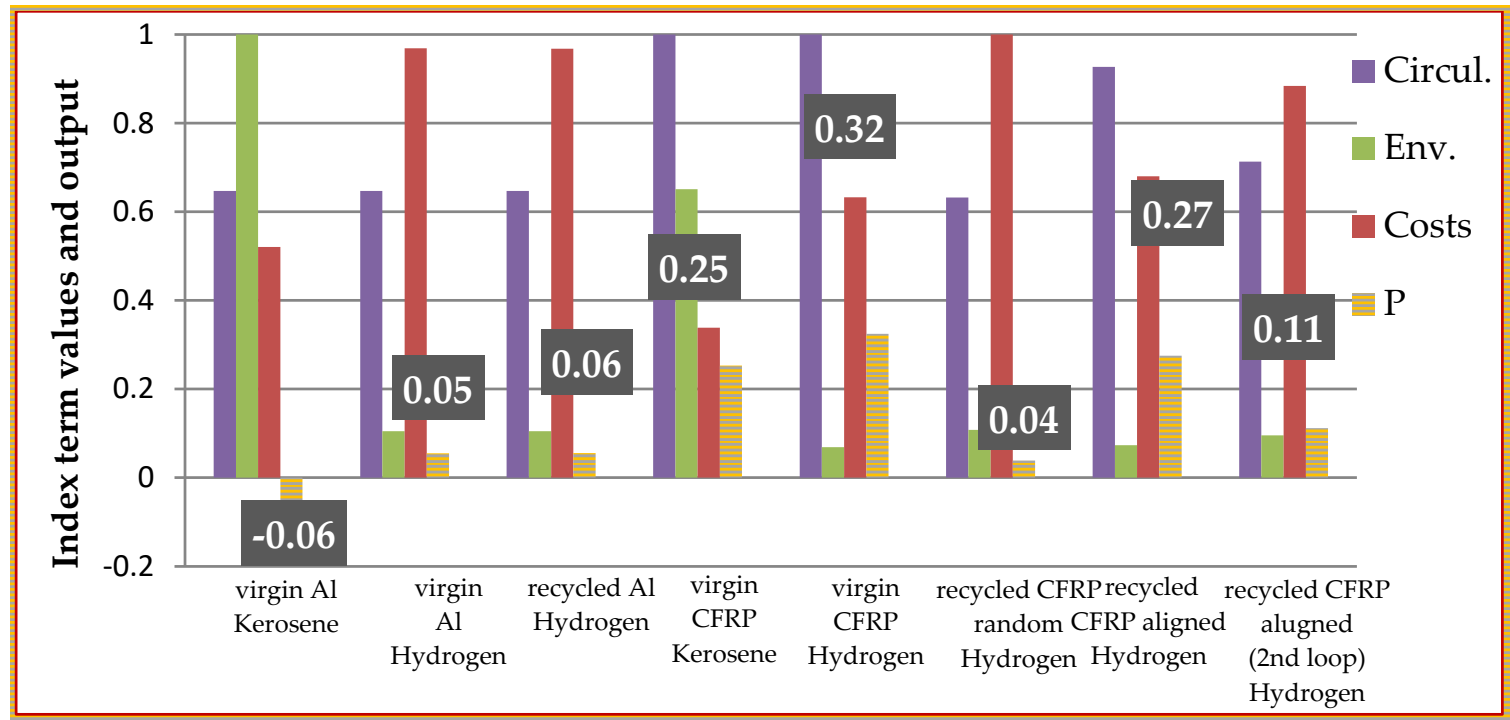

Figure 7. Index term values and final output: comparison analysis number 3.

As expected, variation of the weight factors (Figures 6 and 7) based on the considerations of Section 3.2.1 (Tables 3 and 4) had a considerable effect on the final index values, as well as on the difference gaps between the investigated components. Nevertheless, the ranking of the considered components was not significantly affected, except for some slight ranking order exchanges between components for which different fuels were considered.

\section{Conclusions}

The implementation of circular economy principles is being advocated with increasing frequency as a way of achieving the goals of sustainable development. In this context, new tools are required to support decision-makers in introducing practices which promote circular economies. Circular economy indicators (CEIs) alone are not able to assess the overall performance of circular strategies at different levels. Hence, they need to be complemented by LCA data to verify both the sustainability and circularity of the investigated system, as well as decrease the probability of mistakes in the interpretation of the results. 
The present work aimed to contribute to the assessment of the impact of material selection on aviation sustainability from a circular economy perspective in a concise and holistic manner. To this end, a comprehensive decision support tool was introduced which integrates LCA data and metrics and a suitable quality-based CEI at the material/component level. By integrating circularity indicators and LCA metrics into the proposed tool, tradeoffs between sustainability aspects and circularity can be addressed. The proposed tool was developed to support stakeholders in identifying and selecting the best-performing materials that meet their defined needs and preferences, expressed through a finite set of conflicting criteria and accounting for technical, environmental, and economic aspects. The tool is capable of accounting for the type of fuel implemented, as well as the quality degradation of the materials which have undergone one or more recycling loops. To reduce subjectivity when determining the importance of each of the considered criteria, the tool was coupled with a multi-criteria decision analysis (MCDA) methodology.

To demonstrate the feasibility of the tool, two primary aviation materials were considered, i.e., aluminum and CFRP. To identify the best-performing material while accounting for the type of fuel used, the holistic tool/index introduced in the present study was implemented for the assessment and ranking of the different components considered. To compensate for variations in the material properties between the investigated components, thickness was adjusted to achieve the same mechanical properties. The final ranking of the considered components highlights the clear advantage of virgin CFRP under the scope of hydrogen fuel propulsion, followed by the CFRP component composed of recycled aligned fibers. The tool was found to be sensitive to variations in the weight factor with regards to the final output values and the difference gaps among the investigated components. Clearly, the accuracy of the output values is influenced by methodological choices, assumptions, and data reliability; therefore, the output of the tool is only as accurate and reliable as the input data are. Therefore, standardized procedures should be defined to ensure the validity and transparency of such assessments, which will be investigated by the authors in future studies. Another consideration for future studies regards upgrading the current tool to extend its application from the component to the aircraft subsystem level (e.g., the entire wing or fuselage, etc.).

In the aviation sector, the use phase dominates the total life cycle impact; therefore, the environmental impact and costs are driven by component weight. As a consequence, the impact due to material production and component manufacturing has a small relative contribution to the total life cycle impact of a material/component: This fact acts as a barrier to the exploitation of recycled components for closed-loop aviation applications, especially for high-performance ones. In this context, recycled materials from the aeronautics industry seem to be much more suitable for use in sectors with less energy-intensive lifespans, such as the automotive sector.

Author Contributions: Conceptualization, D.N.M. and S.G.P.; methodology, D.N.M. and S.G.P.; software, D.N.M. and S.G.P.; validation, D.N.M. and S.G.P.; formal analysis, D.N.M. and S.G.P.; investigation, D.N.M. and S.G.P.; resources, D.N.M. and S.G.P.; data curation, D.N.M. and S.G.P.; writing-original draft preparation, D.N.M. and S.G.P.; writing-review and editing, D.N.M. and S.G.P.; visualization, D.N.M. and S.G.P.; supervision, S.G.P.; project administration, S.G.P.; funding acquisition, S.G.P. All authors have read and agreed to the published version of the manuscript.

Funding: The APC was funded by the Aerospace journal.

Institutional Review Board Statement: Not applicable.

Informed Consent Statement: Not applicable.

Data Availability Statement: Not applicable.

Conflicts of Interest: The authors declare no conflict of interest. 


\section{References and Note}

1. European Commission. Flightpath 2050, Europe's Vision for Aviation; Report of the High Level Group on Aviation Research, Directorate-General for Research and Innovation, Directorate General for Mobility and Transport; European Commission: Brussels, Belgium, 2011; p. 28.

2. Communication from the Commission to the European Parliament, the European Council, the Council, the European Economic and Social Committee and the Committee of the Regions the European Green Deal com/2019/640 final. Available online: https:/ / www.eea.europa.eu/policy-documents/communication-from-the-commission-to-1 (accessed on 9 January 2022).

3. Graver, B.; Rutherford, D.; Zheng, S. $\mathrm{CO}_{2}$ Emissions from Commercial Aviation: 2013, 2018, and 2019; Report of the ICCT (The International Council on Clean Transportation); ICCT: Binangonan, Philippines, 2020.

4. Gnadt, A.R.; Speth, R.L.; Sabnis, J.S.; Barrett, S.R.H. Technical and environmental assessment of all-electric 180-passenger commercial aircraft. Prog. Aerosp. Sci. 2019, 105, 1-30. [CrossRef]

5. Léonard, P.; Nylander, J. Sustainability assessment of composites in aero-engine components. In Proceedings of the Design Society: DESIGN Conference, Cavtat, Croatia, May 2020; pp. 1989-1998.

6. Markatos, D.N.; Katsiropoulos, C.; Tserpes, K.; Pantelakis, S. A holistic End-of-Life (EoL) Index for the quantitative impact assessment of CFRP waste recycling techniques. Manuf. Rev. 2021, 8, 18.

7. Zhang, J.; Chevali, V.S.; Wang, H.; Wang, C.H. Current status of carbon fibre and carbon fibre composites recycling. Compos. Part B Eng. 2020, 193, 108053. [CrossRef]

8. Dincer, I.; Acar, C. A review on potential use of hydrogen in aviation applications. Int. J. Sustain. Aviat. 2016, 2, 74-100. [CrossRef]

9. Acar, C.; Dincer, I. The potential role of hydrogen as a sustainable transportation fuel to combat global warming. Int. J. Hydrogen Energy 2020, 45, 3396-3406. [CrossRef]

10. Bicer, Y.; Dincer, I. Life cycle evaluation of hydrogen and other potential fuels for aircrafts. Int. J. Hydrogen Energy 2017, 42, 10722-10738. [CrossRef]

11. Saidani, M.; Yannou, B.; Leroy, Y.; Cluzel, F.; Kendall, A. A taxonomy of circular economy indicators. J. Clean. Prod. 2019, 207, 542-559. [CrossRef]

12. Rigamonti, L.; Mancini, E. Life cycle assessment and circularity indicators. Int. J. Life Cycle Assess 2021, 26, 1937-1942. [CrossRef]

13. Haupt, M.; Zschokke, M. How can LCA support the circular economy?-63rd discussion forum on life cycle assessment, Zurich, Switzerland, November 30, 2016. Int. J. Life Cycle Assess 2017, 22, 832-837. [CrossRef]

14. Mantalovas, K.; Di Mino, G. Integrating circularity in the sustainability assessment of asphalt mixtures. Sustainability 2020, $12,594$. [CrossRef]

15. Niero, M.; Kalbar, P.P. Coupling material circularity indicators and life cycle based indicators: A proposal to advance the assessment of circular economy strategies at the product level. Resour. Conserv. Recycl. 2019, 140, 305-312. [CrossRef]

16. Tapper, R.J.; Longana, M.L.; Norton, A.; Potter, K.D.; Hamerton, I. An evaluation of life cycle assessment and its application to the closed-loop recycling of carbon fibre reinforced polymers. Compos. Part B Eng. 2020, 184, 107665. [CrossRef]

17. Meng, F.; McKechnie, J.; Pickering, S.J. An assessment of financial viability of recycled carbon fibre in automotive applications Compos. Part A Appl. Sci. 2018, 109, 207-220. [CrossRef]

18. The Aluminum Association. The Environmental Footprint of Semi-Finished Aluminum Products in North America; A Life Cycle Assessment Report; The Aluminum Association: Arlington County, VA, USA, 2013.

19. Deng, Y. Life Cycle Assessment of Biobased Fibre-Reinforced Polymer Composites. Ph.D. Thesis, KU Leuven, Science, Engineering \& Technology, Leuven, Belgium, 2014.

20. Shanley, F.R. Weight-Strength Analysis of Aircraft Structures, 2nd ed.; Dover Publications: Mineola, NY, USA, 1960.

21. Patton, R.; Li, F. Causes of Weight Reduction Effects of Material Substitution on Constant Stiffness Components; SAE Technical: Warrendale, PA, USA, 2002.

22. Li, F.; Patton, R.; Moghal, K. The relationship between weight reduction and force distribution for thin wall structures. Thin-Walled Struct. 2005, 43, 591-616. [CrossRef]

23. Meng, F.; Olivetti, E.A.; Zhao, Y.; Chang, J.C.; Pickering, S.J.; McKechnie, J. Comparing life cycle energy and global warming potential of carbon fiber composite recycling technologies and waste management options. ACS Sustain. Chem. Eng. 2018, 6 , 9854-9865. [CrossRef]

24. EU Website. Electricity Price Statistics. Available online: https:/ / ec.europa.eu (accessed on 22 October 2021).

25. Suzuki, T.; Jun Takahashi, J. Prediction of energy intensity of carbon fiber reinforced plastics for mass-produced passenger cars In Proceedings of the Ninth Japan International SAMPE Symposium, Tokyo, Japan, 29 November-2 December 2005.

26. Ghosh, T.; Kim, H.C.; De Kleine, R.; Wallington, T.J.; Bakshi, B.R. Life cycle energy and greenhouse gas emissions implications of using carbon fiber reinforced polymers in automotive components: Front subframe case study. Sustain. Mater. Technol. 2021, 28, e00263. [CrossRef]

27. Dér, A.; Dilger, N.; Kaluza, A.; Creighton, C.; Kara, S.; Varley, R.; Herrmann, C.; Thiede, S. Modelling and analysis of the energy intensity in polyacrylonitrile (PAN) precursor and carbon fibre manufacturing. J. Clean. Prod. 2021, 303, 127105. [CrossRef]

28. AAA Air Support Website. Roll Forming and AAA Air Support. Available online: https://www.aaaairsupport.com (accessed on 22 October 2021).

29. Bachman, J.; Hidalgo, C.; Bricout, S. Environmental analysis of innovative sustainable composites with potential use in aviation sector-A life cycle assessment review. Sci. Chin. Technol. Sci. 2017, 60, 1301-1317. [CrossRef] 
30. Hill, C.; Norton, A. Report_LCA Database of Environmental Impacts to Inform Material Selection Process; JCH Industrial Ecology Ltd. DACOMAT Project; European Union: Brussels, Belgium, 2019.

31. Kim, H.C.; Wallington, T.J. Life cycle assessment of vehicle lightweighting: A physics-based model to estimate use-phase fuel consumption of electrified vehicles. Environ. Sci. Technol. 2016, 50, 11226-11233. [CrossRef] [PubMed]

32. Duflou, J.; Deng, Y.; Van Acker, K.; Dewulf, W. Do fiber-reinforced polymer composites provide environmentally benign alternatives? A life-cycle-assessment-based study. MRS Bull. 2012, 37, 374-382. [CrossRef]

33. Larsen, 1.; Schuster, A.; Kim, J.; Kupke, M. Path planning of cooperating industrial robots using evolutionary algorithms. Procedia Manuf. 2018, 17, 286-293. [CrossRef]

34. Airliners Website. Aircraft Technical Data and Specifications. Airbus A320. Available online: https://www.airliners.net (accessed on 22 October 2021).

35. Das, S.K.; Kaufman, J.G. Recycling aluminum aerospace alloys. Adv. Mater. Process 2008, 166, 34-35.

36. Zhao, D.; Guo, Z.; Xue, J. Research on scrap recycling of retired civil aircraft. IOP Conf. Ser. Earth Environ. Sci. 2021, 657, 012062. [CrossRef]

37. Karuppannan Gopalraj, S.; Kärki, T. A study to investigate the mechanical properties of recycled carbon fibre/glass fibre-reinforced epoxy composites using a novel thermal recycling process. Processes 2020, 8, 954. [CrossRef]

38. Meng, F.; Cui, Y.; Pickering, S.; McKechnie, J. From aviation to aviation: Environmental and financial viability of closed-loop recycling of carbon fibre composite. Compos. Part B Eng. 2020, 200, 108362. [CrossRef]

39. Longana, M.L.; Ong, N.; Yu, H.; Potter, K.D. Multiple closed loop recycling of carbon fibre composites with the HiPerDiF (High Performance Discontinuous Fibre) method. Compos. Struct. 2016, 153, 271-277. [CrossRef]

40. Katsiropoulos, C.V.; Pantelakis, S.G. A novel holistic index for the optimization of composite components and manufacturing processes with regard to quality, life cycle costs and environmental performance. Aerospace 2020, 7, 157. [CrossRef]

41. Vo Dong, P.A.; Azzaro-Pantel, C.; Cadene, A. Economic and environmental assessment of recovery and disposal pathways for CFRP waste management. Resour. Conserv. Recycl. 2018, 133, 63-75. [CrossRef]

42. Kalkanis, K.; Psomopoulos, C.S.; Kaminaris, S.; Ioannidis, G.; Pachos, P. Wind turbine blade composite materials-End of life treatment methods. Energy Procedia 2019, 157, 1136-1143. [CrossRef]

43. Ighravwe, D.E.; Oke, S.A. A multi-criteria decision-making framework for selecting a suitable maintenance strategy for public buildings using sustainability criteria. J. Build. Eng. 2019, 24, 100753. [CrossRef]

44. SuperDecisions Software: www.superdecisions.com. A program that is free to download and use for several months. For more information contact Creative Decisions Foundation, or email rozann@creativedecisions.net.

45. Constellium. Airware®2198-T8 Fuselage Sheet. Technical Datasheet; Constellium: Paris, France, 2017.

46. European Commission's Critical Raw Materials List. Available online: https:/ / aluminiumtoday.com (accessed on 22 October 2021).

47. Pinheiro Melo, S.; Barke, A.; Cerdas, F.; Thies, C.; Mennenga, M.; Spengler, T.S.; Herrmann, C. Sustainability assessment and engineering of emerging aircraft technologies-Challenges, methods and tools. Sustainability 2020, 12, 5663. [CrossRef] 